\title{
RELAÇÕES FILOGENÉTICAS E DIVERSIDADE DE ISOLADOS DE Guignardia SPP ORIUNDOS DE DIFERENTES HOSPEDEIROS NAS REGIÕES ITS1-5,8S-ITS2 ${ }^{1}$
}

\author{
ESTER WICKERT ${ }^{2}$, ANTONIO DE GOES ${ }^{3}$, ELIANA GERTRUDES DE MACEDO LEMOS ${ }^{4}$, \\ ANDRESSADE SOUZA $^{5}$, ÉRICO LEANDRO DA SILVEIRA ${ }^{6}$, \\ FERNANDADIAS PEREIRA ${ }^{5}$, DAVI RINALDO 5
}

RESUMO- Fungos do gênero Guignardia são frequentemente isolados em diferentes espécies de plantas, sendo muitas vezes caracterizados como fungos endofíticos. Entretanto, algumas espécies deste fungo, a exemplo de G. citricarpa e G. psidii, são causadores de importantes doenças que afetam culturas agrícolas, como a Mancha-Preta dos Citros (MPC) e a podridão dos frutos de goiabeira, respectivamente. Também são apontados como causadores de manchas foliares em diferentes espécies de frutíferas e também em outras culturas. Este trabalho teve o objetivo de isolar, identificar e caracterizar a diversidade genética existente entre isolados de Guignardia oriundos de citros, mangueira, goiabeira, eucaliptos, jabuticabeira e pitangueira através da análise da sequência de DNA do cístron ITS1-5,8S-ITS2. Verificou-se que os isolados obtidos pertencem às espécies G. citricarpa e G. mangiferae. Entretanto, dois grupos encontrados em mangueira não puderam ser identificados em nível de espécie com base em sua sequência de DNA em função da baixa similaridade com as sequências de diferentes espécies de Guignardia já depositadas em banco de dados. Desta forma, goiabeira, eucaliptos, jabuticabeira e pitangueira são hospedeiras de G. mangiferae, enquanto os citros hospedam duas formas, G. citricarpa e G. mangiferae. Já a mangueira é hospedeira de G. mangiferae e de dois outros grupos ainda não identificados. Verificou-se ainda que isolados de Guignardia obtidos de sintomas de podridão de fruto de goiabeira foram identificados como G. mangiferae.

Termos para indexação: fungos endofíticos, patogênicos, variabilidade genética.

\section{PHYLOGENETIC RELATIONSHIPS AND DIVERSITY OF Guignardia spp ISOLATED FROM DIFFERENT HOSTS ON ITS1-5,8S-ITS2 REGION}

\begin{abstract}
Fungi of Guignardia genera are commonly isolated from different plant species and most of the time they are characterized as endophytics. However, some species of this genus, as G. citricarpa and G. psidii are known as causal agents of serious diseases that affect cultures, such as the Citrus Black Spot and the guava fruit rot, respectively. They are also responsible for diseases that cause foliar spots in different fruit species and also in other cultures. This work has the objective of isolate, identify and characterize the genetic diversity present among Guignardia isolates obtained from citrus, mango, guava, eucalyptus, Brazilian grape tree and Surinam cherry by analysis of DNA sequence from cístron ITS1-5,8SITS2. It was verified that the obtained isolates belong to G. mangiferae and G. citricarpa species. Two different Guignardia types, that were found in mango, could not be identified in species, and do not belong to none of the species deposited in GenBank. So, this work found that mango, guava, eucalyptus, Brazilian grape tree and Surinam cherry host only G. mangiferae, whereas citrus hosts G. mangiferae and G. citricarpa species. Mango hosts three different Guignardia, G. mangiferae and two others types that remain without identification of the species level. It was also verified that isolates of Guignardia obtained from guava fruit rot symptoms were identified as G. mangiferae.
\end{abstract}

Index Terms: endophytic fungi, pathogenic, genetic variability.

1(Trabalho 233-08). Recebido em: 09-09-2008. Aceito para publicação em: 16-02-2009.Artigo extraído dos resultados
obtidos pelo Projeto Fapesp 04/10560-4- Pós-doutoramento do primeiro autor.
${ }^{2}$ Pós-Doutoranda em Genética e Melhoramento de Plantas. Epagri - C.P. 277- Itajaí-SC. Bolsista Fapesp.
esterwickert@epagri.sc.gov.br
${ }^{3}$ Prof. Titular do Depto. de Tecnologia FCAV/UNESP.Bolsista Produtividade em Pesquisa CNPq. egerle@fcav.unesp.br
${ }^{4}$ Prof. Adjunto do Depto. de Tecnologia FCAV/UNESP.Bolsista Produtividade em Pesquisa CNPq. agoes@fcav.unesp.br
${ }^{5}$ Graduandos do curso de Agronomia da FCAV/UNESP - Jaboticabal-SP. Depto. de Fitossanidade. Bolsistas CNPq/PIBIC e
FAPESP. andressa_unesp@yahoo.com, fekimera@hotmail.com, davi.rinaldo@yahoo.com.
${ }^{6}$ Doutorando em Microbiologia Agropecuária. Depto. de Tecnologia FCAV/UNESP. Bolsista CAPES. ericosilveira@gmail.com

Rev. Bras. Frutic., Jaboticabal - SP, v. 31, n. 2, p. 360-380, Junho 2009 


\section{INTRODUÇÃO}

O gênero Guignardia (Reino Fungi, Filo Acomycota, Classe Dothideomycetes, Ordem Botryosphaeriales, Família Botryosphaeriaceae) compreende cerca de 330 espécies identificadas até o momento, sendo muitas delas ainda sem a fase anamórfica identificada (Crouws et al., 2004). Neste gênero, encontram-se espécies consideradas endofíticas, como G. mangiferae, e também espécies patogênicas, como G. citricarpa e G. psidii. Entre as espécies patogênicas, G. citricarpa é o agente causal de uma importante doença para a citricultura, a Mancha-Preta dos Citros (MPC) (Sutton e Waterston, 1966). Já G. psidii é apontada como a responsável por podridões de pós-colheita que acarretam grandes perdas, principalmente em frutos de goiabeira (Tozello e Ribeiro, 1998).

Embora seja causadora de manchas foliares em mangueira, a espécie G. mangiferae foi isolada em ampla gama de outros hospedeiros e, em muitos casos, considerada endofítica para o hospedeiro, por ter sido isolada a partir de tecidos assintomáticos. Estes hospedeiros incluem plantas tropicais brasileiras, como peroba-rosa (Apidosperma polineuron), cajuaçu (Anacardium giganteum), aroeira (Myracrodreun urundeuva), cajá (Spondias mombin), sucupira (Bowdichia nitida) e fedegoso (Cassia occidentalis) (Rodrigues et al., 2004). Plantas cítricas também são reconhecidamente hospedeiras de G. mangiferae (Baayen et al., 2002), embora a mesma seja considerada endofítica por não estar relacionada a nenhum tipo de sintoma de doença apresentada por esta planta.

Em vários estudos envolvendo fungos, o cístron que codifica o RNA ribossomal (rDNA) tem sido utilizado para estudos de sistemática molecular e filogenia. O grande número de cópias em série desta sequência e a uniformidade das mesmas, geralmente mantida através da evolução harmônica, são as maiores vantagens dos genes e regiões intergênicas para a análise filogenética (White et al., 1990). Por serem mais conservadas, as regiões que compreendem os genes $18 \mathrm{~S}$ e 28S podem ser utilizadas para diferenciação de indivíduos em nível de gênero e espécie (Gargas \& Depriest, 1996), enquanto as regiões espaçadoras ITS e IGS, por acumularem maior variabilidade genética, são mais utilizadas para estudos de discriminação de espécies, de subpopulações ou mesmo de indivíduos de uma mesma espécie (Ristaino et al., 1998; Dresler-Nurmi et al., 1999; Baciarelli-Falini et al., 2006).

No Brasil, apesar de terem sido detectadas plantas hospedeiros de fungos do gênero
Guignardia, pouco se conhece acerca de quais seriam as espécies do fungo, de outros possíveis hospedeiros e da diversidade genética associada às populações em cada hospedeiro. Este trabalho teve por objetivo isolar e identificar isolados de Guignardia oriundos de citros, mangueira, goiabeira, eucaliptos, jabuticabeira e pitangueira, bem como caracterizar a diversidade genética existente através da análise da sequência de DNA do cístron ITS1-5,8S-ITS2.

\section{MATERIAL E MÉTODOS}

Isolamento e teste do meio aveia-ágar. Os isolamentos foram realizados em três espécies cítricas, laranja-‘Azeda’ (Citrus aurantium), limaácida 'Tahiti' (Citrus latifolia) e laranja-‘Pera’(Citrus sinensis). Todas as folhas foram coletadas no município de Conchal-SP. Em lima-ácida 'Tahiti' e laranja-‘Pera', foram coletadas folhas de 30 diferentes plantas em pomar, enquanto em laranja-‘Azeda’ foram coletadas folhas aleatoriamente em plantas ao longo de uma fileira. A partir de tecidos de folhas de lima ácida 'Tahiti ', laranja-‘Azeda’ e laranja-'Pera', foram obtidos fragmentos de aproximadamente $5 \mathrm{~mm}^{2}$, retirados da parte central de um dos lóbulos do limbo foliar. Esses fragmentos foram imersos em etanol 70\% por um minuto e, posteriormente, em solução de hipoclorito de sódio:água esterilizada 1:3 v/v, por 3 minutos, e enxágue em água esterilizada por 30 segundos. Após secagem desse material em papel de filtro estéril, tais fragmentos foram justapostos em placas de Petri contendo meio BDA (BatataDextrose-Ágar) e incubados em condição ambiente por 7 dias. Após esse período, colônias típicas de Phyllosticta spp. obtidas foram repicadas para obtenção de isolados puros. A seguir, foi realizado o isolamento dos fungos a partir das lesões de frutos de laranja-'Pera', coletados também em pomar de Conchal-SP. Nos frutos, os isolamentos foram dirigidos a lesões dos tipos mancha preta (MP) ou mancha-dura, falsa melanose (FM), mancha-sardenta (MS) mancha-trincada (MT) e mancha- rendilhada (MR). A mesma amostragem em folhas foi realizada em mangueira (Mangifera indica) (amostragem em Conchal-SP e Jaboticabal-SP) e goiabeira (Psidium guajava) (Jaboticabal-SP e Monte Alto-SP). As amostragens em eucaliptos (Eucalytus sp.), pitangueira (Eugenia uniflora) e jabuticabeira (Myrciaria cauliflora) foram realizadas unicamente em Jaboticabal-SP.

Todos os isolados obtidos foram submetidos ao teste do meio de cultura aveia-ágar (AA), utilizado para distinguir os isolados patogênicos e endofíticos 
de Guignardia spp. (Baayen et al., 2002; Baldassari et al., 2008). Nesse estudo, um disco de $0,5 \mathrm{~cm}^{2} \mathrm{da}$ colônia dos isolados foi colocada no centro de placas contendo o meio AA. Foram realizadas quatro réplicas para cada isolado, que foram incubadas a $25^{\circ} \mathrm{C} \pm 1{ }^{\circ} \mathrm{C}$ e fotoperíodo $12 / 12$ h.a $25^{\circ} \mathrm{C}$, por um período de 7 - 10 dias, quando então foram avaliados quanto à formação ou não de halo amarelo característico.

Extração de DNA, amplificação e sequenciamento das regiões ITS1-5,8S-ITS2. O DNA dos isolados foi extraído conforme KuramaeIzioka (1997). Para a amplificação das regiões ITS15,8S-ITS2, utilizou-se do par de primers ITS1/ITS4 (White et al., 1990), obtendo-se o fragmento esperado de cerca de 650 pb. As reações de PCR foram realizadas, utilizando-se de tampão $1 \mathrm{X}$ (KCl 50 mM, Tris-HCl 200 mM, pH 8,4); 0,2 mM de dNTPs, 1,5 U de Taq DNA polimerase, $2 \mathrm{mM}$ de $\mathrm{MgCl}_{2}, 5$ pmol de cada primer, 60 ng de DNA e água pura estéril q.s.p. $20 \mu \mathrm{L}$. O DNA foi amplificado em termociclador PTC-100 Programmable Thermal Controller - MJ Research, inc., com um ciclo inicial de $94^{\circ} \mathrm{C}$, por 2 minutos; 39 ciclos a $94^{\circ} \mathrm{C}$, por 1 minuto; $60^{\circ} \mathrm{C}$, por 1 minuto, e $72^{\circ} \mathrm{C}$, por 1 minuto e 30 segundos) com um ciclo final de 10 minutos, a $72^{\circ} \mathrm{C}$. As amostras amplificadas foram submetidas a eletroforese em gel de agarose a 1,2\%, contendo brometo de etídio $(0,5 \mathrm{mg} / \mathrm{mL})$ e padrão de concentração pGem e após visualizadas sob luz UV em equipamento de fotodocumentação (GEL DOC 1000 - BioRad). O DNA do fragmento amplificado de cada isolado foi então submetido a PCR de sequenciamento utilizando-se do DYEnamic ET Dye Terminator Kit (GE Healthcare), conforme instruções do fabricante. O programa de termociclagem foi o mesmo utilizado para a amplificação dos fragmentos desta região. As amostras com os fragmentos foram precipitadas com a isopropanol a $75 \%$ e lavadas com etanol a $70 \%$, ressuspendidas em $3 \mathrm{~mL}$ de "loading buffer” padrão (5:1 formamida deionizada/ $50 \mathrm{mM}$ EDTA, pH 8.0), aquecidas a $95^{\circ} \mathrm{C}$, por 2 minutos, e aplicadas em gel de sequenciamento. A eletroforese foi conduzida em sequenciador $A B I$ Prism 3700 DNA Sequencer (Applied Biossytems, Foster City, USA). As regiões ITS de cada isolado foi submetida a sequenciamento por duas vezes para maior confiabilidade da sequência obtida.

Análise das sequências de DNA obtidas. Os eletroferogramas obtidos foram visualizados e analisados por meio do software ABI Analysis Data Collection e convertidos em sequências de nucleotídeos por meio do software DNA Sequencing Analysis Software Versão 3.3. Os eletroferogramas gerados pelo processo de sequenciamento foram submetidos ao pacote de programas Phred/Phrap/ Consed (Gordon et al., 1998) e Sequencher ${ }^{\mathrm{TM}}$ (versão 4.05 (Gene Codes Corp, Ann Arbor, USA)), para a verificação da sua qualidade, alinhamento e corte das extremidades. As sequências obtidas foram submetidas a comparação em banco de dados através da ferramenta BLAST (Altschull et al., 1997) para verificar sua similaridade em relação a sequências já depositadas no banco de dados NCBI. As sequências foram então alinhadas e utilizadas na construção de dendrogramas para a verificação da similaridade dos isolados obtidos entre si, e para as análises de distância genética de acordo com o hospedeiro e entre hospedeiros diferentes.

Análise das relações genéticas. Os dendrogramas foram construídos pelo método da Distância, com o algoritmo de agrupamento Neighbor Joining (Saitou e Nei, 1987) e modelo de substituição de Kimura-2-parameter (Kimura, 1980) através do software MEGA(Versão 3.1) (Kumar et al., 2004). Para assegurar a confiabialidade do agrupamento, foi realizado teste de bootstrap (Felsenstein, 1985) com 1.000 repetições com o mesmo software. Em cada arquivo, foram incluídas sequências pertencentes a diferentes espécies de Guignardia spp.: G. citricarpa clone 75 (ID:AF346782.1); G. citricarpa (ID: AF346772.1); G. mangiferae voucher ICMP 8336 (ID:AY816311.1); G.mangiferae (ID: AM403717.1); G. laricina (ID:AB041245.1); G. philoprina (ID:AB095507.1); G. philoprina specimen-voucher CBS 447.68 (ID: AF312014); G. aesculi (ID:AB095504.1); G. vaccinii (ID:AB041244.1);G. bidwellii (ID:AB095511.1); G. bidwellii (ID: AB095505); G. bidwellii (ID: AB095509); G. gaultheriae (ID: AB095506.1); G. gaultheriae (ID: AB095506); Phyllosticta pyrolae (ID: AF312010); Phyllosticta pyrolae (ID: AB041242) e Phyllosticta spinarum (ID: AF312009). Essas sequências foram utilizadas para verificar a similaridade das sequências obtidas com as depositadas no banco (GenBank). Foram selecionadas sequências de todas as espécies disponíveis no banco, embora nem todas as espécies conhecidas e identificadas tenham sequências depositadas no GenBank. Essas sequências do banco foram selecionadas em detrimento de outras disponíveis das mesmas espécies por terem maior tamanho em pares de bases e por estarem com identificação completa. Sequências de outros Ascomicetos como Fusarium subglutinans (ID: FSU38556), F. oxysporum (ID: FJ233193.1), 
Colletotrichum gloeosporioides (ID: FJ434136.1), C. lagenarium (ID: EU622278.1) e Glomerella acutata (ID: AB273195.1) foram utilizadas como outgroup. As sequências obtidas por este trabalho foram depositadas no GenBank, e seu número de acesso (ID) encontra-se no Anexo 1.

Distância genética intra e interespecífica. Índices de distância genética foram calculados entre os grupos de isolados de G. mangiferae de mesma planta, diferentes plantas e também entre diferentes hospedeiros e regiões geográficas, para isolados endofíticos e para patogênicos. Esses índices também foram calculados para os isolados identificados como G. citricarpa oriundos de citros e também para os isolados que não puderam ser identificados em nível de espécie. As estimativas de distância genética foram utilizadas para inferir a divergência genética dentro e entre grupos de isolados (Nei, 1972). Essa distância genética entre isolados de uma mesma planta foi estimada pela média aritmética da distância entre cada um dos indivíduos, comparados dois a dois (Nei e Kumar, 2000). Já a distância entre grupos de isolados de diferentes plantas, hospedeiros ou região geográfica foi calculada pela média aritmética de todas as distâncias entre os dois grupos (Nei e Kumar, 2000). Esses valores foram obtidos utilizandose do padrão de substituição de nucleotídeos Kimura2-Parameter (Kimura, 1980) através do software MEGA (3.1 version) (Kumar et al., 2004).

\section{RESULTADOS}

Isolamento e teste do meio aveia-ágar. Para este estudo, foram obtidos isolados de diferentes hospedeiros e regiões geográficas, conforme apresentados na Tabela 1.

Todos os isolados obtidos foram submetidos ao teste de meio AA, observando-se que os isolados apresentaram a resposta descrita na literatura para isolados patogênicos e endofíticos (Baayen et al., 2002; Baldassari et al., 2008). Verificou-se que uma terceira e diferente resposta foi apresentada por alguns isolados deste estudo. O teste do meio aveiaágar dividiu os isolados em três categorias (Figura 1 e Tabela 2): o primeiro grupo não apresentou formação de halo amarelo, o que caracterizou os isolados como não-patogênicos ou endofíticos, sendo este grupo formado por isolados de folhas de lima-ácida 'Tahiti', de laranja-'Azeda', mangueira, goiabeira, eucaliptos, pitangueira e jabuticabeira. Outro grupo apresentou a formação de halo característico de isolados patogênicos, de cor amarela, composto por isolados oriundos de lesões de MPC, de folhas de lima-ácida 'Tahiti' e de laranja'Azeda'. O terceiro grupo apresentou a formação de um halo branco-amarelado, ainda não descrito em literatura, sendo composto por isolados oriundos exclusivamente de mangueira.

Análise das sequências de DNA obtidas. As regiões ITS1-5,8S-ITS2 de todos os isolados mostraram similaridade igual ou maior do que $90 \%$ com sequências de fungos pertencentes ao gênero Guignardia depositadas no NCBI, demonstrando que todos os isolados deste trabalho pertencem ao gênero Guignardia. As sequências das regiões ITS15,8S-ITS2 também se mostraram eficientes em identificar a maioria dos isolados em nível de espécie. Quando as sequências foram comparadas uma a uma no banco de dados, foi possível identificar isolados da espécie G. mangiferae e G. citricarpa com similaridades superiores a $97 \%$ em todos os hospedeiros, embora para um grupo de isolados oriundos de mangueira não tenha sido encontrada similaridade suficiente para a identificação da espécie. Em mangueira, foram encontrados três diferentes grupos de Guignardia, dos quais somente um pôde ser identificado de acordo com as regiões ITS. O grupo identificado como $G$. mangiferae apresentou similaridade superior a $97 \%$ com sequências depositadas no banco de dados NCBI classificadas como sendo desta espécie. Os outros dois grupos, diferentes de $G$. mangiferae e também diferentes entre si, mostraram similaridades menores do que 97\% com sequências depositadas no banco de dados. Os isolados MC apresentaram similaridade de $92 \%$ a $94 \%$ com G. philoprina e também com G. pyrolae (ou Phyllosticta pyrolae). Já o grupo M/MM apresentou similaridade de 91 a 93 \% com G. citricarpa. Estes dois grupos, M/MM e MC, apresenta uma similaridade de $92 \%$ com ambas as espécies G. mangiferae e G. citricarpa, indicando não pertencerem a nenhuma das duas, quando analisados individualmente por BLAST em banco de dados.

Análise das relações genéticas. Os isolados obtidos de lesões de MPC em frutos de laranja-'Pera' agruparam-se com sequências de DNA depositadas em banco de dados pertencentes a G. citricarpa (Figura 2), assim como alguns isolados oriundos de folhas assintomáticas de lima-ácida 'Tahiti' (Figura 3), de laranja-'Pera’ (Figura 4) e de laranja-'Azeda’ (Figura 5). Já outros isolados obtidos de folhas assintomáticas de lima- ácida 'Tahiti', laranja-'Pera' e de laranja-'Azeda’ agruparam-se com sequências do banco pertencentes a G. mangiferae. Todos os 
isolados obtidos de eucaliptos (Figura 6), pitangueira (Figura 7) e jabuticabeira (Figura 8) também se agruparam no dendrograma com G. mangiferae, assim como todos os isolados obtidos de goiabeira (Figura 9), inclusive os obtidos de sintomas de podridão de fruto. Em mangueira (Figura 10), além das sequências identificadas como pertencentes a G. mangiferae, dois grupos de isolados não apresentaram similaridade suficiente para serem identificados em nível de espécie, embora no dendrograma um grupo dos isolados M e MM tenha-se aproximado de $G$. citricarpa, demonstrando serem geneticamente mais próximos a esta espécie. O outro grupo, formado por isolados MC, aproximou-se de diferentes espécies, como G. bidwellii, G. philoprina, G. aesculi e G. gaultheriae, além de Phyllostica spinarum e $P$. pyrolae. Um dos grupos de Guignardia sp. identificado como $\mathrm{MM} / \mathrm{M}$ foi encontrado colonizando plantas de mangueira em duas regiões geográficas diferentes, Jaboticabal e Conchal-SP, enquanto os isolados identificados como MC foram encontrados somente em Jaboticabal-SP. As sequências consenso obtidas para cada grupo de isolados da Tabela 2 não demonstraram alteração da identificação obtida com as sequências individuais, embora os isolados MC tenham-se aproximado de Phyllosticta spinarum (Figura 11), embora provavelmente não pertençam a esta espécie.

Distância genética intra e intergrupos. Para as análises de distância genética intra e intergrupos, os isolados foram divididos de acordo com sua resposta ao meio aveia-ágar, identificação de acordo com as regiões ITS1-5,8S-ITS2, hospedeiro e região geográfica, obtendo-se assim 18 grupos de isolados, de acordo com a Tabela 2. Verificou-se que o grupo de isolados obtidos de lima-ácida 'Tahiti' e identificados como G. mangiferae, seguidos pelos isolados de pitangueira e jabuticabeira, apresentaram a maior distância genética entre si. Embora todos tenham sido classificados como não-patogênicos pelo meio aveia-ágar e como G. mangiferae pelas regiões ITS1-5,8S-ITS2, estes grupos apresentaram maior diversidade genética entre seus componentes. Os isolados oriundos de goiabeira e também identificados como G. mangiferae, tanto de folhas como de frutos sintomáticos e assintomáticos, mostraram menores índices de distância genética e, portanto, apresentando maior homogeneidade genética.

A análise entre os grupos de isolados demonstrou que as menores distâncias genéticas foram apresentadas entre grupos de isolados de mesma espécie, tanto G. citricarpa quanto $G$. mangiferae, mesmo quando oriundos de diferentes hospedeiros (Tabela 3). Os isolados identificados como G. citricarpa e G. mangiferae apresentaram uma distância genética média de 0.10 entre si. Já os isolados oriundos de mangueira, que não puderam ser identificados em nível de espécie, apresentaram uma distância genética maior em relação a $G$. mangiferae do que em relação a G. citricarpa, embora a distância genética observada tenha demonstrado que os mesmos são distintos em relação a estas duas espécies e também entre si.

\section{DISCUSSÃO}

Os resultados obtidos através das sequências de DNA das regiões ITS1-5,8S-ITS2 mostraram que plantas de citros são hospedeiras da espécie patogênica $G$. citricarpa e também de $G$. mangiferae. Entretanto, apesar de serem hospedeiras da espécie patogênica, laranja- 'Azeda’ e lima-ácida ‘Tahiti’não apresentam sintomas da MPC, mesmo quando em presença de grandes quantidades de fontes de inóculo ou próximas a pomares com alta incidência da doença. As amostragens para lima-ácida 'Tahiti' e laranja-'Azeda' deste trabalho foram realizadas em Conchal-SP, em locais de alta incidência da doença. O fato de lima-ácida 'Tahiti' ser hospedeira da espécie patogênica $G$. citricarpa foi anteriormente relatada (Baldassari et al., 2008), mas o fato da laranja'Azeda' apresentar comportamento semelhante constitui-se uma informação nova e de grande importância. Assim, o fato de hospedarem a espécie patogênica sem apresentarem sintomas torna estas duas espécies cítricas interessantes para programas de melhoramento visando à resistência a MPC. Embora a natureza do mecanismo que impede o aparecimento de sintomas nestas duas espécies seja ainda desconhecido, é provável que o mesmo seja estrutural, genético, metabólico ou oriundo de alguma combinação entre estes fatores.

Em plantas cítricas, também foi observado que isolados das duas espécies, G. citricarpa e $G$. mangiferae, coexistem em uma mesma planta, uma vez que ambas foram isoladas em folhas assintomáticas de uma mesma planta em laranja‘Azeda’, laranja-‘Pera’ e lima-ácida ‘Tahiti’. Desta forma, é provável que não haja competição pelo mesmo nicho por estas duas espécies, da mesma forma que em mangueira, onde G. mangiferae coexiste em uma mesma planta com os outros dois grupos de Guignardia ainda não identificados.

Os resultados obtidos pelo teste do meio AA e pelo sequenciamento das regiões ITS1-5,8S-ITS2 mostraram concordância entre si. Os isolados que 
apresentaram formação de halo amarelo agruparamse com alta similaridade (maior ou igual a 97\%) com sequências obtidas do banco de dados pertencentes a G. citricarpa, enquanto os isolados que não apresentaram formação de halo agruparam-se com sequências pertencentes a G. mangiferae também com alta similaridade (maior ou igual a 97\%). Baldassari et al. (2008) também utilizaram esse meio de cultura na identificação prévia de seus isolados e constataram que os isolados que apresentaram halo amarelo em meio aveia-ágar se mostraram patogênicos em testes de patogenicidade a campo, enquanto os que não mostraram formação de halo também não causaram sintomas em diferentes variedades de laranjas-doces. Segundo esse autor, a utilização do meio aveia-ágar mostrou-se uma alternativa simples, eficiente e relativamente rápida na distinção entre isolados de patogênicos e endofíticos para citros.

Ao contrário da espécie G. citricarpa, que entre os hospedeiros deste trabalho foi encontrada unicamente em citros, a espécie G. mangiferae demonstrou ter uma ampla gama de hospedeiros, taxonomicamente muito diferentes entre si. Assim, plantas já descritas como hospedeiras de $G$. mangiferae, como mangueira (Mangifera indica L.), bananeira (Musa sp.), citros (Citrus sp.), goiabeira (Psidium guajava), eucaliptos (Eucalytus sp.) e plantas da família Ericaeae (Okane et al., 2001) somam-se aos novos hospedeiros deste fungo encontrados por este trabalho, pitangueira (Eugenia uniflora) e jabuticabeira (Myrciaria cauliflora). No caso de jabuticabeira e pitangueira, aparentemente G. mangiferae as coloniza como endofítico, pois nenhum sintoma de doença foi associado à presença do fungo na planta. Os resultados obtidos por este trabalho através da análise das regiões ITS1-5,8SITS2 indicam que isolados obtidos das diferentes espécies de plantas pertencem a uma mesma espécie, G. mangiferae.

A análise destas regiões também indica que isolados obtidos de folhas e frutos assintomáticos de goiabeira, bem como em frutos sintomáticos para podridão, apresentam similaridade suficiente nesta região para serem todos identificados como $G$. mangiferae. Desta forma, mesmo que isolados causadores de podridão em frutos de goiabeira sejam descritos na literatura como G. psidii (Tozello e Ribeiro, 1998) - e apesar de não haver disponibilidade de sequências classificadas como G. psidii no banco de dados até 08-12-2008 para fins de comparação -, os isolados obtidos de sintomas de podridão por este trabalho mostraram similaridade superior a $98 \%$, e em alguns casos de $100 \%$, com sequências de $G$. mangiferae. A posição de todos os isolados obtidos de goiabeira no dendrograma apresenta-se muito próxima a G. mangiferae e distante das outras espécies de Guignardia utilizadas como referência.

Assim, a exemplo de outras espécies de fungos, é possível que G. mangiferae comporte-se de forma endofítica para algumas plantas, como citros, e endofítica e patogênica em outras, como goiabeira. A maioria, senão todas as plantas estudadas apresentam fungos endofíticos, que, na maioria das vezes, são benéficos para a planta, embora haja relatos de endofíticos que se tornaram patógenos sob determinadas condições (Kogel et al.,2006). Os mesmos autores inferem que, uma vez que a condição doença é considerada uma exceção nas interações planta-microrganismos, as mesmas podem ser consideradas como um estado desbalanceado de uma simbiose. Outros autores argumentam que, na interação planta-endofíticos há um grau de virulência por parte do fungo, o que permite a infecção e a colonização do hospedeiro, embora os mecanismos de defesa da planta limitem o desenvolvimento do invasor, e, por consequência, não permitem o aparecimento da doença (Schultz e Boyle, 2005).

Outra possibilidade é que $G$. mangiferae e $G$. psidii sejam conspecíficas. Trabalhando com espécies nativas do Japão, Okane et al. (2001) notaram grande similaridade entre os isolados endofíticos obtidos, que identificaram como $G$. endophyllicola, e isolados de G. mangiferae, de tal forma que não era possível diferenciá-los morfológica e molecularmente, e sugeriram que as duas espécies eram conspecíficas. A observação das colônias do fungo obtido de folhas assintomáticas e dos frutos sintomáticos de goiabeira, neste trabalho, mostrou que não é possível diferenciá-las visualmente, além de apresentarem o mesmo tipo de resposta ao teste do meio aveia-ágar, bem como sequências de DNA altamente similares das regiões ITS1-5,8S-ITS2 utilizadas para a análise, o que reforça a hipótese da conspecificidade.

Uma vez que isolados obtidos de goiabeira, bem como de mangueira e dos outros hospedeiros deste estudo foram identificados como pertencentes a G. mangiferae, é provável que esta mesma espécie tenha muitos outros hospedeiros ainda não identificados no Brasil. No Japão, isolados de Guignardia sp. foram obtidos de folhas saudáveis de 94 espécies de plantas pertencentes a 69 diferentes gêneros (Okane et.al., 2003), o que leva a supor que o número de hospedeiros de Guignardia no Brasil seja elevado. Baayen et al. (2002) descreveram $G$. mangiferae como um simbionte de grande sucesso 
por colonizar um grande número de espécies arbóreas de grande distribuição mundial.

A observação de uma mesma espécie de fungo colonizando diferentes hospedeiros, como é o caso de G. mangiferae, pode ser devida ao fato de que esta espécie não apresenta coevolução com seu hospedeiro e que saltos evolucionários para outros hospedeiros, muitas vezes não relacionados, ocorrem frequentemente, ou ainda que os mesmos coevoluem com seu hospedeiro, mas que a extinção de espécies é frequente (Rodrigues et al., 2004). Os mesmos autores ressaltam que a ocorrência de $G$. mangiferae em diferentes espécies de plantas deve ser devida a estes saltos evolucionários. A uniformidade observada entre os grupos de isolados de G. mangiferae de diferentes hospedeiros também pode ser devida à presença de fluxo gênico entre as populações, uma vez que os diferentes hospedeiros são frequentemente encontrados espacialmente próximos.

Em relação aos isolados obtidos de mangueira e que não encontraram homologia em banco de dados para serem identificados em nível de espécie, é possível que estes dois grupos pertençam a outras espécies, ainda não descritas e/ ou identificadas no Brasil, e para as quais ainda não existem sequências ITS1-5,8S-ITS2 depositadas em banco de dados. Os isolados M/MM e MC apresentaram uma distância genética maior em relação a $G$. mangiferae do que em relação a $G$. citricarpa, embora a distância genética observada tenha demonstrado que os mesmos são distintos em relação a estas duas espécies e também entre si, evidenciando a probabilidade de que são espécies distintas das utilizadas como padrões e que possuem sequências depositadas em banco de dados. Assim, verifica-se que plantas de mangueira são hospedeiras de $G$. mangiferae e também de duas outras espécies de Guignardia sp., aqui neste trabalho identificadas como MM/M e MC, esta última encontrada somente em Jaboticabal-SP. Embora G. citricarpa tenha sido relatada como causadora de manchas foliares em manga na Flórida (McMillan, 1986), e que os isolados MM/M tenham-se mostrado mais próximos desta espécie do que de G. mangiferae, a resposta ao meio aveia-ágar e a similaridade obtida com as regiões ITS1-5,8S-ITS2 foram muito baixas para identificá-las como sendo G. citricarpa, motivo pelo qual se acredita tratar-se de outra espécie. Esta mesma possibilidade é creditada aos isolados identificados como MC.

A utilização de técnicas moleculares na identificação e caracterização de fungos é de grande interesse, principalmente em função da rapidez com que pode ser realizada se comparada com as técnicas convencionais. Técnicas de sequenciamento menos custosas e, por consequência, mais acessíveis, e o contínuo aprimoramento da bioinformática, que possibilita análise de grandes quantidades de dados, têm contribuído consideravelmente para o crescimento exponencial na genômica de fungos (Robbertse et al., 2006; Xu, 2006), bem como têm impulsionado a área da sistemática de fungos, principalmente em relação a mapeamento global de diversidade genética (Robbertse et al., 2006). Embora um dos fatores limitantes para o incremento da filogenética molecular de fungos seja o pequeno número de genes facilmente acessíveis para tal geralmente os genes ribossomais e suas regiões internas - é inegável que a utilização dos mesmos propiciou grandes avanços para a área (Robbertse et al., 2006). Uma vez que um grande número de fungos são reconhecidos como causadores de problemas fitossanitários, e considerando que da maioria destes se conhecem apenas características morfológicas, a possibilidade de utilização de sequências de DNA para sua classificação é de grande importância, e a contínua alimentação de bancos de dados com novas informações acerca de novas espécies de fungos aumenta a precisão na identificação de novos isolados (Bridge et al., 2005; Crouws, 2005). Neste trabalho, verificou-se que as sequências de DNA depositadas em banco de dados foram eficientes para a identificação dos isolados obtidos dos diferentes hospedeiros, sendo que se espera que as sequências obtidas das regiões ITS15,8S-ITS2 destes novos isolados, uma vez depositadas em banco de dados, também auxiliem a identificar ou a refinar a classificação dos já existentes ou de novos isolados. Assim sendo, espera-se também que a contínua alimentação destes bancos por diferentes pesquisadores possa informar, num futuro próximo e com mais precisão, a quais espécies pertencem os dois grupos de isolados encontrados em mangueira. 
TABELA 1 - Hospedeiros, região geográfica e tecido de origem dos isolados, sigla de acordo com o hospedeiro e número de isolados obtidos em cada amostragem.

\begin{tabular}{ccccc}
\hline Hospedeiro & Local de origem & Tecido & Sigla & $\mathbf{N}^{\mathbf{0}}$ isolados \\
\hline Laranja-Pera & Conchal-SP & Fruto sintomático & PC & 24 \\
Laranja-Pera & Conchal-SP & Folhas assintomáticas & FLP & 11 \\
Laranja-Azeda & Conchal-SP & Folhas assintomáticas & LAC & 9 \\
Lima-ácida Tahiti & Conchal-SP & Folhas assintomáticas & LC & 26 \\
Mangueira & Jaboticabal-SP & Folhas assintomáticas & M e MC & 20 \\
Mangueira & Conchal-SP & Folhas assintomáticas & MM & 22 \\
Goiabeira & Jaboticabal-SP & Folhas assintomáticas & G & 25 \\
Goiabeira & Monte Alto-SP & Folhas assintomáticas & GM & 10 \\
Goiabeira & Monte Alto-SP & Fruto assintomático & GF & 3 \\
Goiabeira & Monte Alto-SP & Fruto sintomático & GP & 3 \\
Eucalipto & Jaboticabal-SP & Folhas assintomáticas & Eu & 12 \\
Pitangueira & Jaboticabal-SP & Folhas assintomáticas & Pit & 24 \\
Jabuticabeira & Jaboticabal-SP & Folhas assintomáticas & Jabot & 5 \\
\hline
\end{tabular}

TABELA 2- Número de isolados por grupo de acordo com hospedeiro e resposta ao teste do meio aveiaágar, e distância genética apresentada pelos isolados de um mesmo grupo.

\begin{tabular}{ccccc}
\hline Grupos & $\mathrm{N}^{\mathrm{o}}$ isolados & Resposta ao meio aveia-ágar & Distância intragrupo & ITS1-5,8S-ITS2 \\
\hline PC & 24 & Com halo amarelo & 0.0116 & G. citricarpa \\
\hline FLP-E & 3 & Sem halo & 0.0103 & G. mangiferae \\
FLP-P & 8 & Com halo amarelo & 0.0006 & G. citricarpa \\
\hline LAC-E & 3 & Sem halo & 0.0243 & G. mangiferae \\
LAC-P & 6 & Com halo amarelo & 0.0054 & G. citricarpa \\
\hline LC-E & 23 & Sem halo & 0.0615 & G. mangiferae \\
LC-P & 3 & Com halo amarelo & 0.0129 & Guignardicarpa \\
\hline M & 13 & Com halo branco-amarelado \\
MM & 20 & Com halo branco-amarelado & 0.0211 & Guignardia sp \\
MM/M-E & 3 & Sem halo & 0.0108 & G. mangiferae \\
MC & 6 & Com halo branco-amarelado & 0.0225 & Guignardia sp \\
\hline G & 25 & Sem halo & 0.0146 & G. mangiferae \\
GM & 10 & Sem halo & 0.0084 & G. mangiferae \\
GF & 3 & Sem halo & 0.0077 & G. mangiferae \\
GP & 3 & Sem halo & 0.0017 & G. mangiferae \\
\hline Eu & 12 & Sem halo & 0.0034 & G. mangiferae \\
\hline Pit & 24 & Sem halo & 0.0007 & G. mangiferae \\
\hline Jabot & 5 & Sem halo & 0.0419 & G. mangiferae
\end{tabular}

E: não patogênico de acordo com comportamento em meio aveia-ágar.

P: patogênico de acordo com comportamento em meio aveia-ágar.

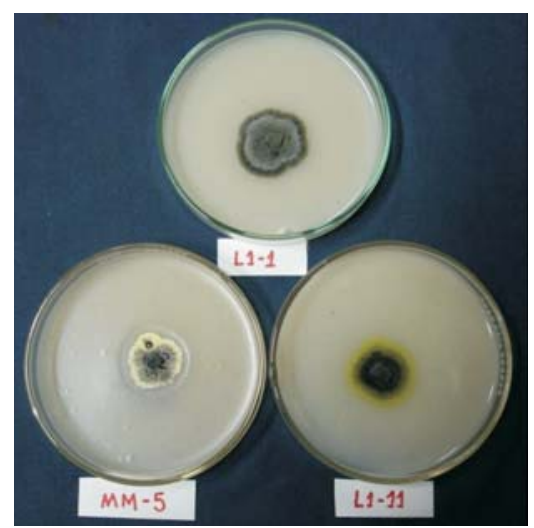

FIGURA 1 - Comportamento de isolados de Guignardia spp. de diferentes hospedeiros em meio aveia-ágar. verifica-se a formação do halo característico de isolados patogênicos em L1-11 (lima-ácida 'Tahiti'), a não-formação para L1-1(lima- ácida 'Tahiti'), caráter para endofíticos (lima-ácida 'Tahiti'), e a formação de halo branco-amarelado para MM-5 (mangueira). 

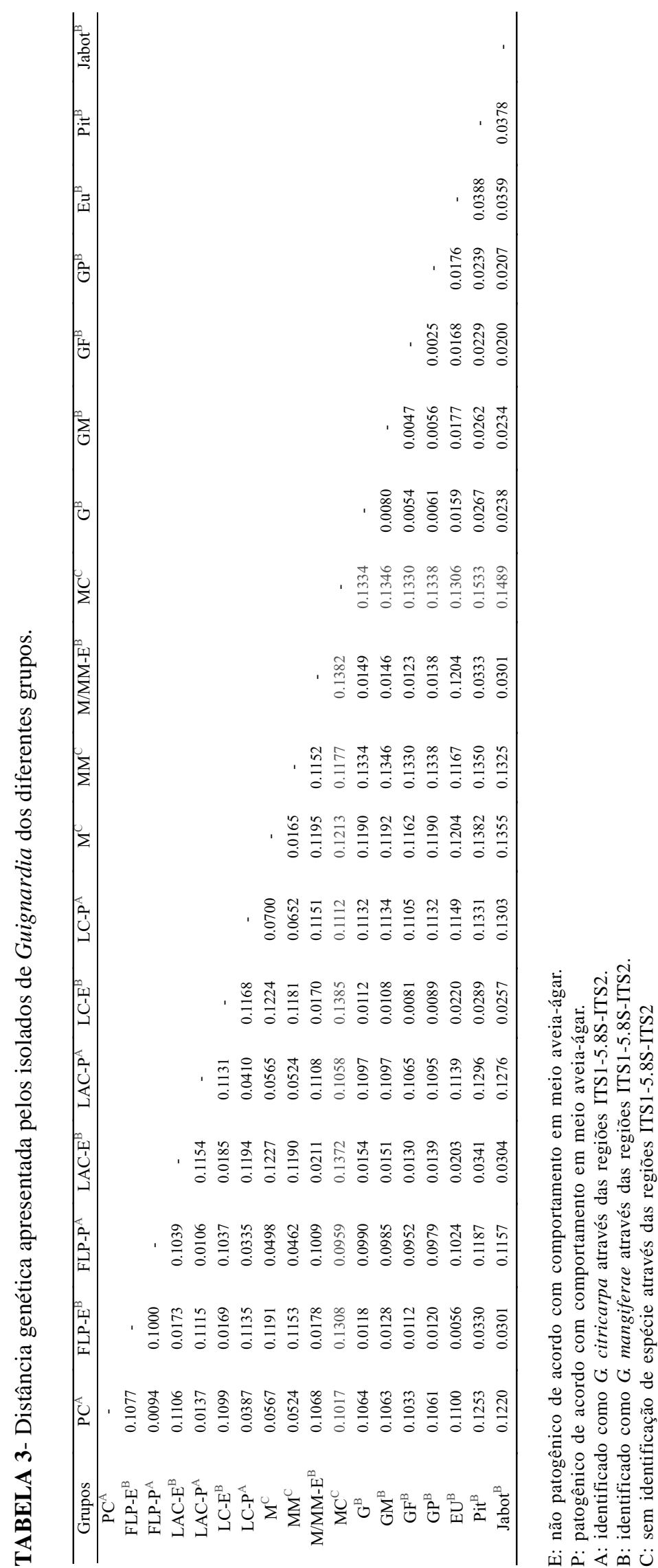

Rev. Bras. Frutic., Jaboticabal - SP, v. 31, n. 2, p. 360-380, Junho 2009 


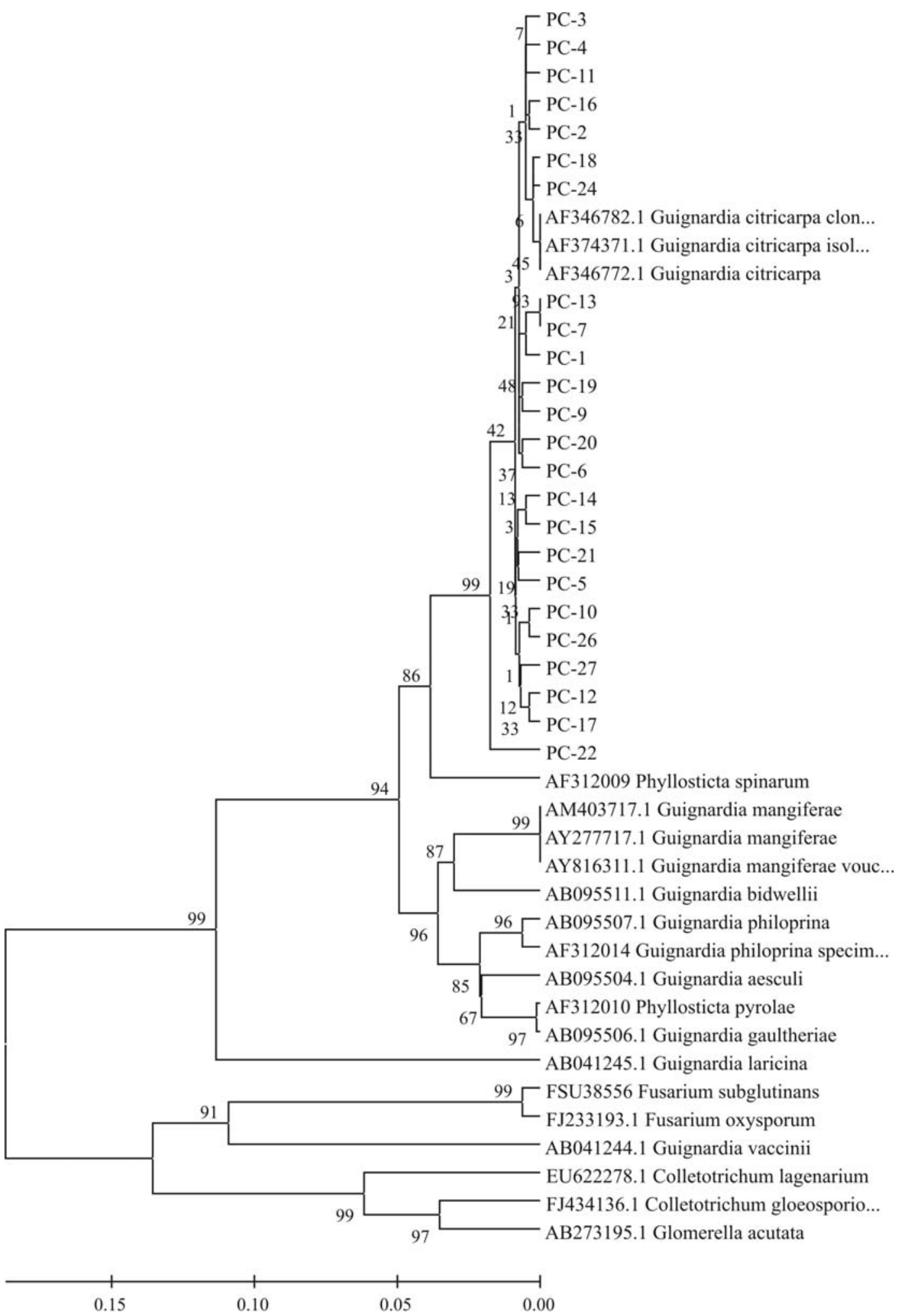

FIGURA 2 - Dendrograma a partir das sequências de DNA das regiões ITS1-5.8S-ITS2 dos isolados obtidos de frutos sintomáticos de MPC em Laranja-Pera de Conchal-SP, mostrando maior similaridade com G. citricarpa. 


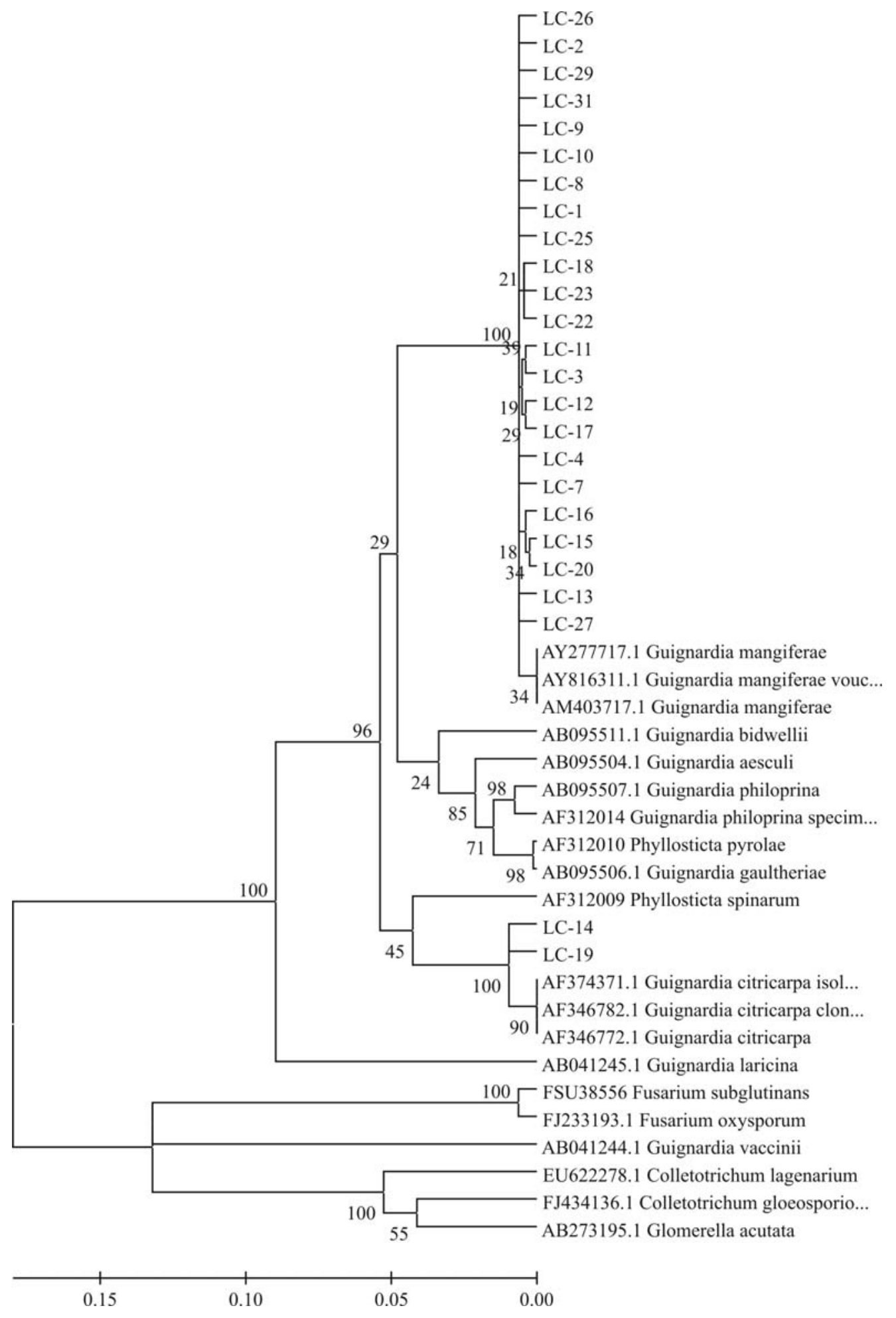

FIGURA 3- Padrão de agrupamento dos isolados de lima-ácida 'Tahiti' de Conchal-SP, através das regiões ITS1-5,8S-ITS2. Verifica-se que esta espécie é hospedeira de G. citricarpa e também de G. mangiferae. 


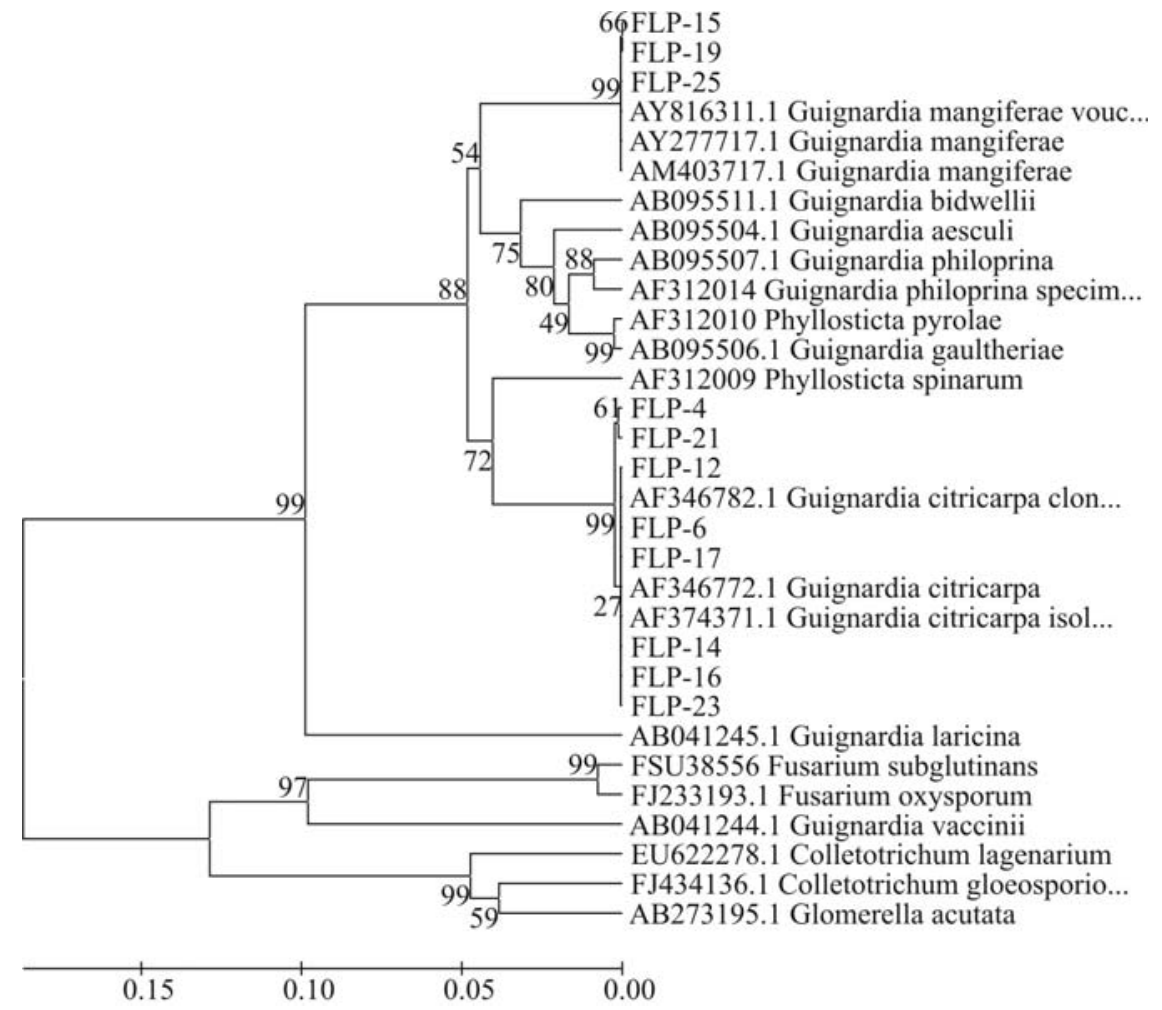

FIGURA 4- Dendrograma dos isolados de folhas assintomáticas de laranja-'Pera' de Conchal-SP, obtido pela análise das regiões ITS1-5,8S-ITS2. Verifica-se que as folhas assintomáticas desta espécie são hospedeiras de G. citricarpa e também de G. mangiferae.

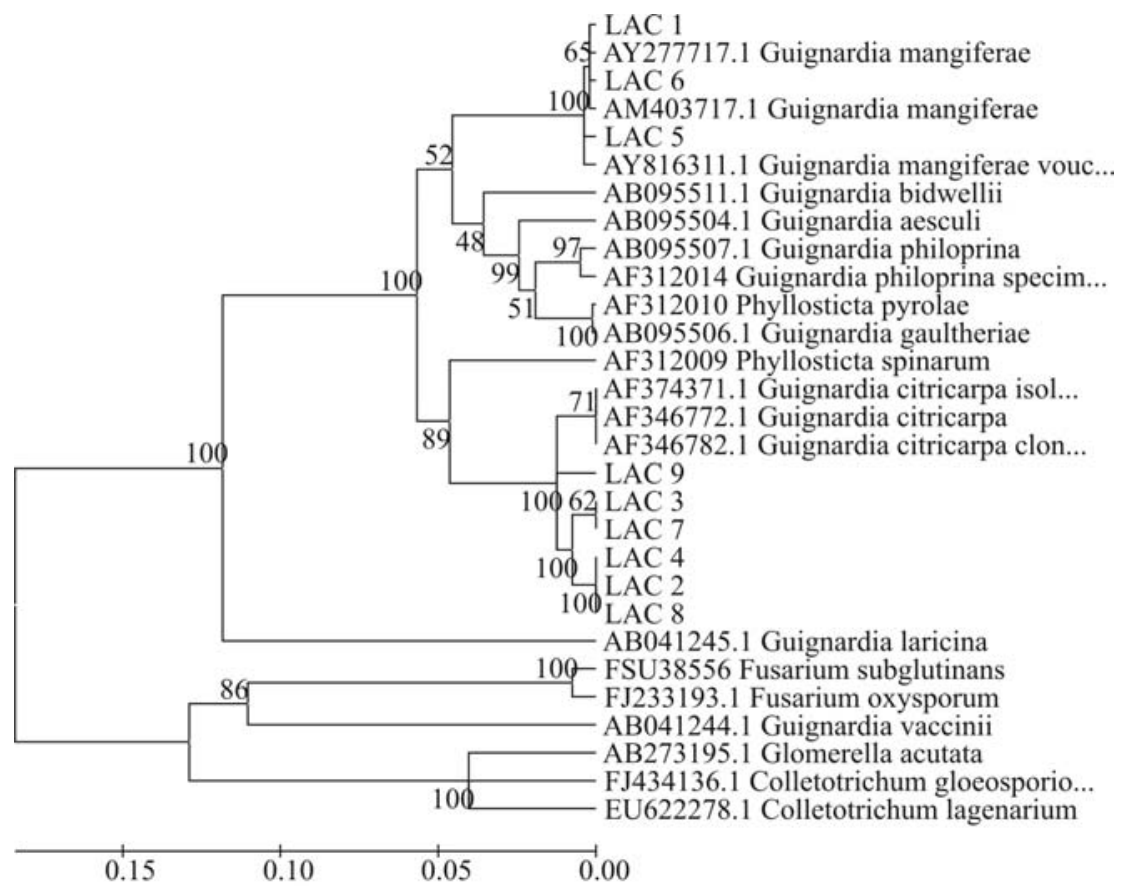

FIGURA 5- Padrão de agrupamento dos isolados obtidos de folhas assintomáticas de laranja- 'Azeda’ em Conchal-SP, através da análise das regiões ITS1-5,8S-ITS2. Verifica-se que esta espécie cítrica hospeda tanto G. citricarpa como G. mangiferae. 


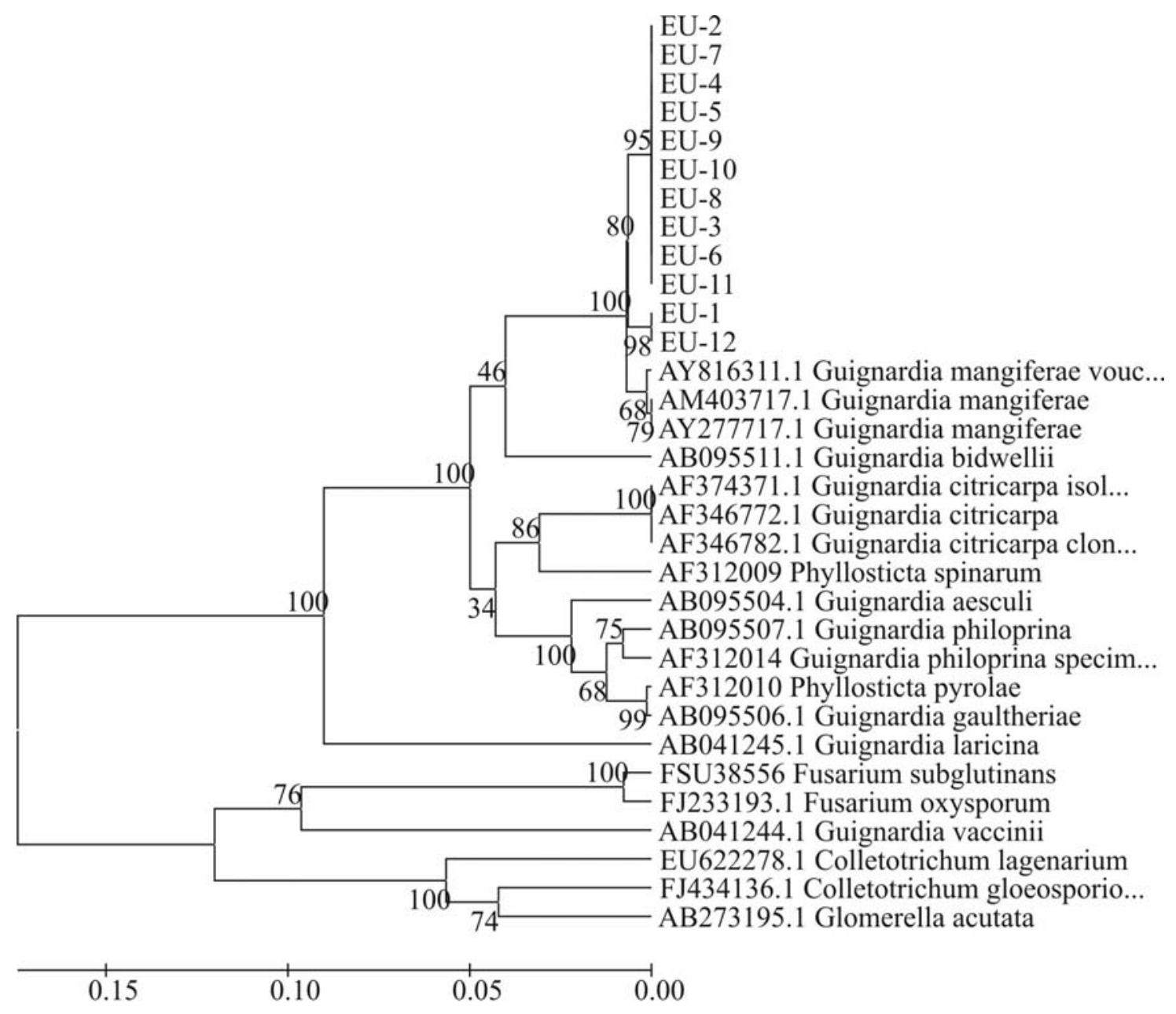

FIGURA 6- Padrão de agrupamento dos isolados obtidos de folhas assintomáticas de eucaliptos em Jaboticabal-SP, obtido pela análise das regiões ITS1-5,8S-ITS2, mostrando que esta planta hospeda G. mangiferae. 


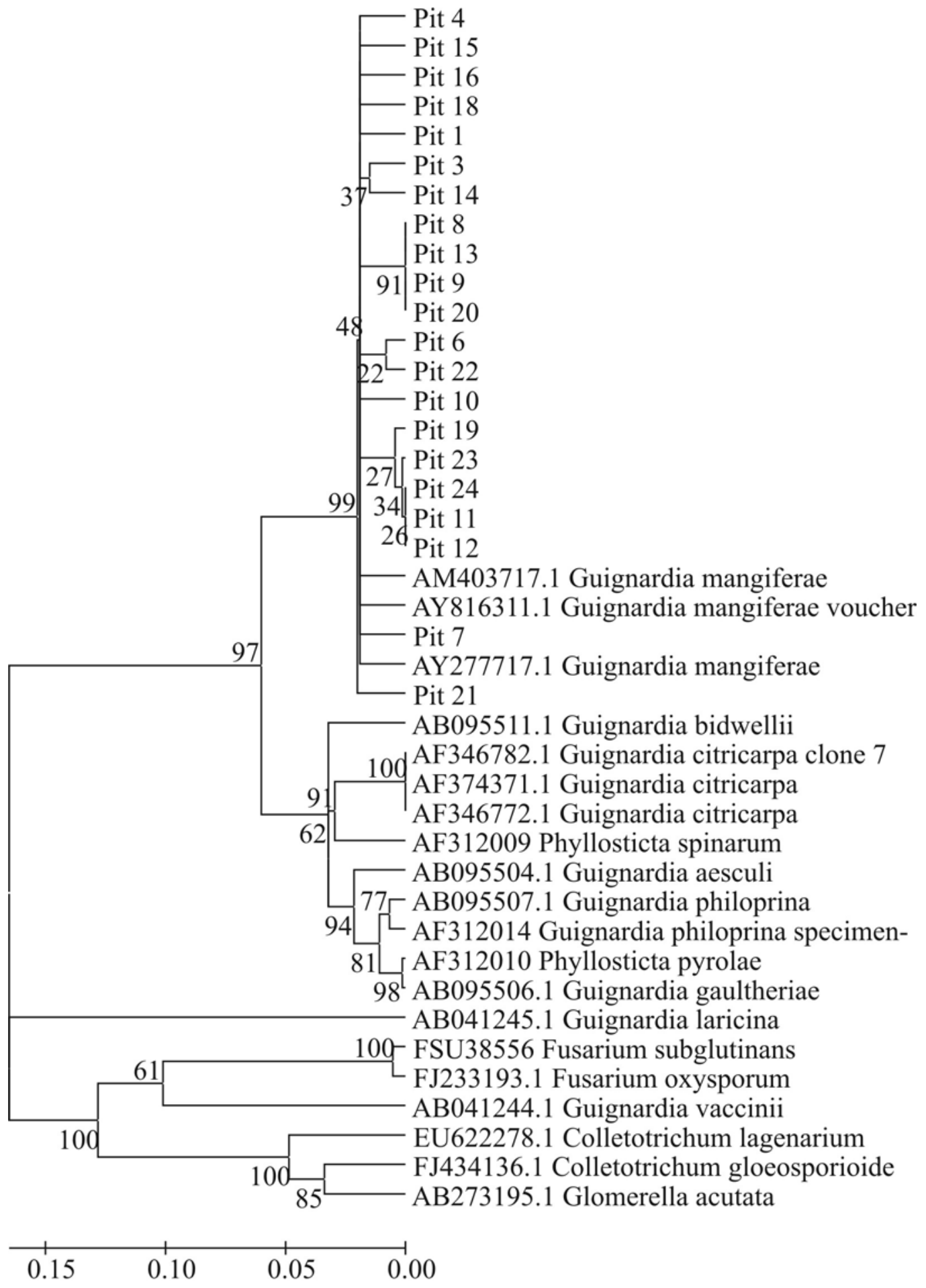

FIGURA 7- Dendrograma dos isolados obtidos de folhas assintomáticas de pitangueira em Jaboticabal-SP, obtido pela análise das regiões ITS1-5,8S-ITS2, mostrando que a mesma é hospedeira de $G$. mangiferae. 


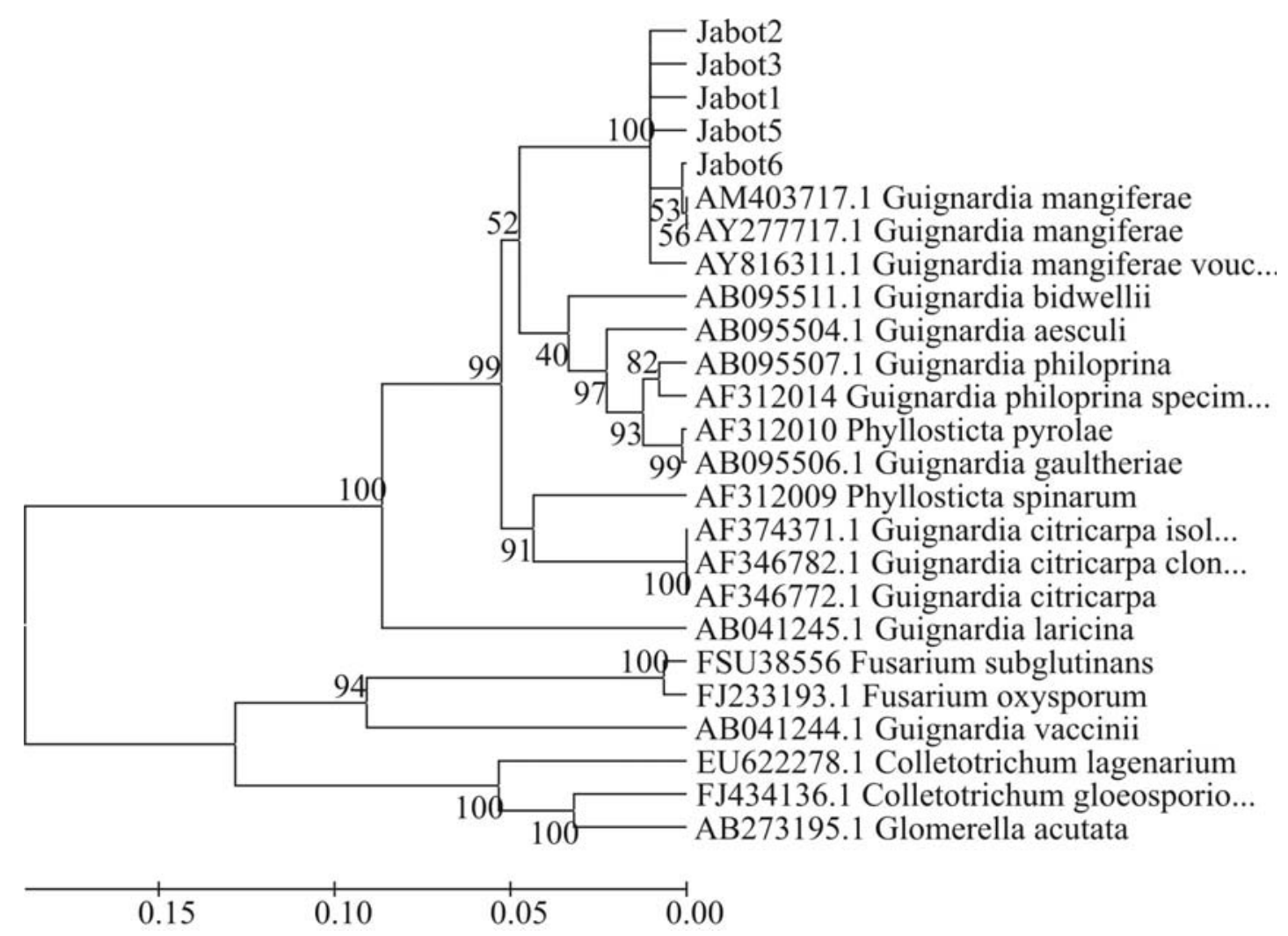

FIGURA 8-Agrupamento dos isolados obtidos de folhas assintomáticas de jabuticabeira em Jaboticabal-SP, obtido pela análise das regiões ITS1-5,8S-ITS2, mostrando que esta planta é hospedeira de G. mangiferae. 


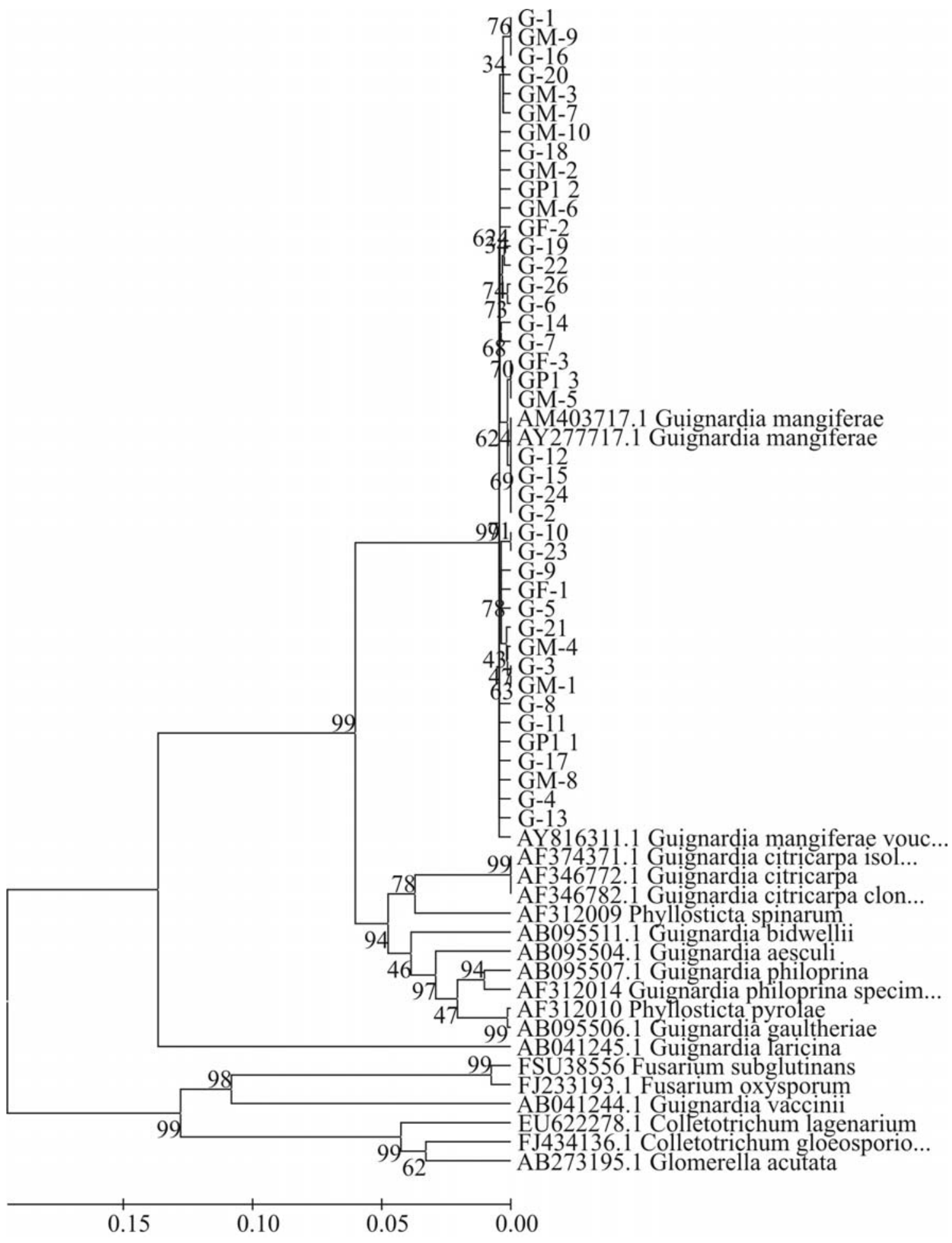

FIGURA 9- Dendrograma dos isolados de goiabeira de folhas assintomáticas obtidas em Jaboticabal-SP (G) e Monte Alto-SP (GM) e de frutos assintomáticos (GF) e sintomáticos (GP) em Monte Alto-SP, através das regiões ITS1-5,8S-ITS2. Observa-se que todos os isolados foram identificados como G. mangiferae 


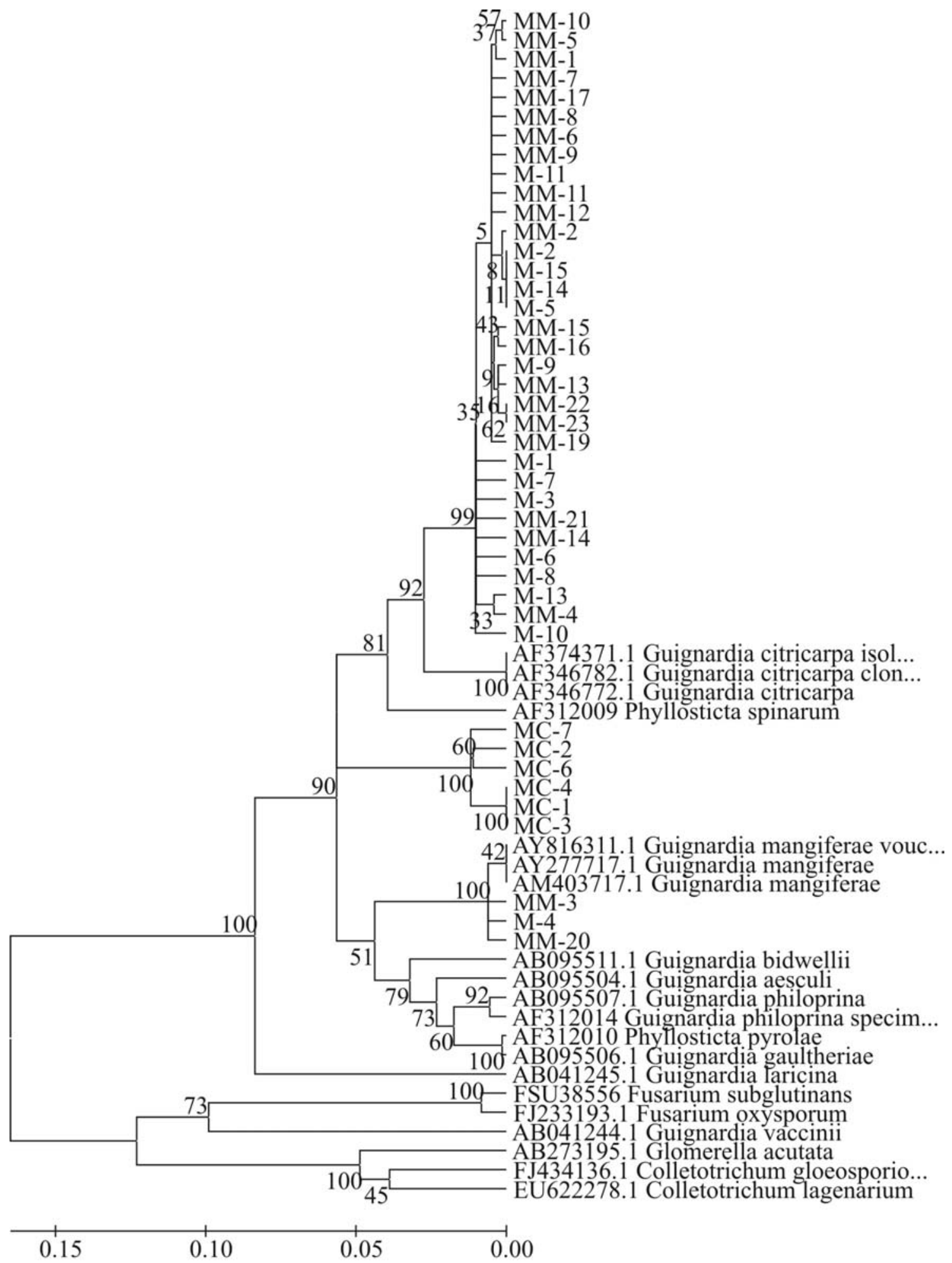

FIGURA 10- Agrupamento dos isolados de mangueira obtidos em Jaboticabal-SP (M e MC) e Conchal-SP (MM) pela análise das regiões ITS1-5,8S-ITS2. Observa-se que a mesma é hospedeira de $G$. mangiferae e também de dois grupos Guignardia não identificados em nível de espécie. 


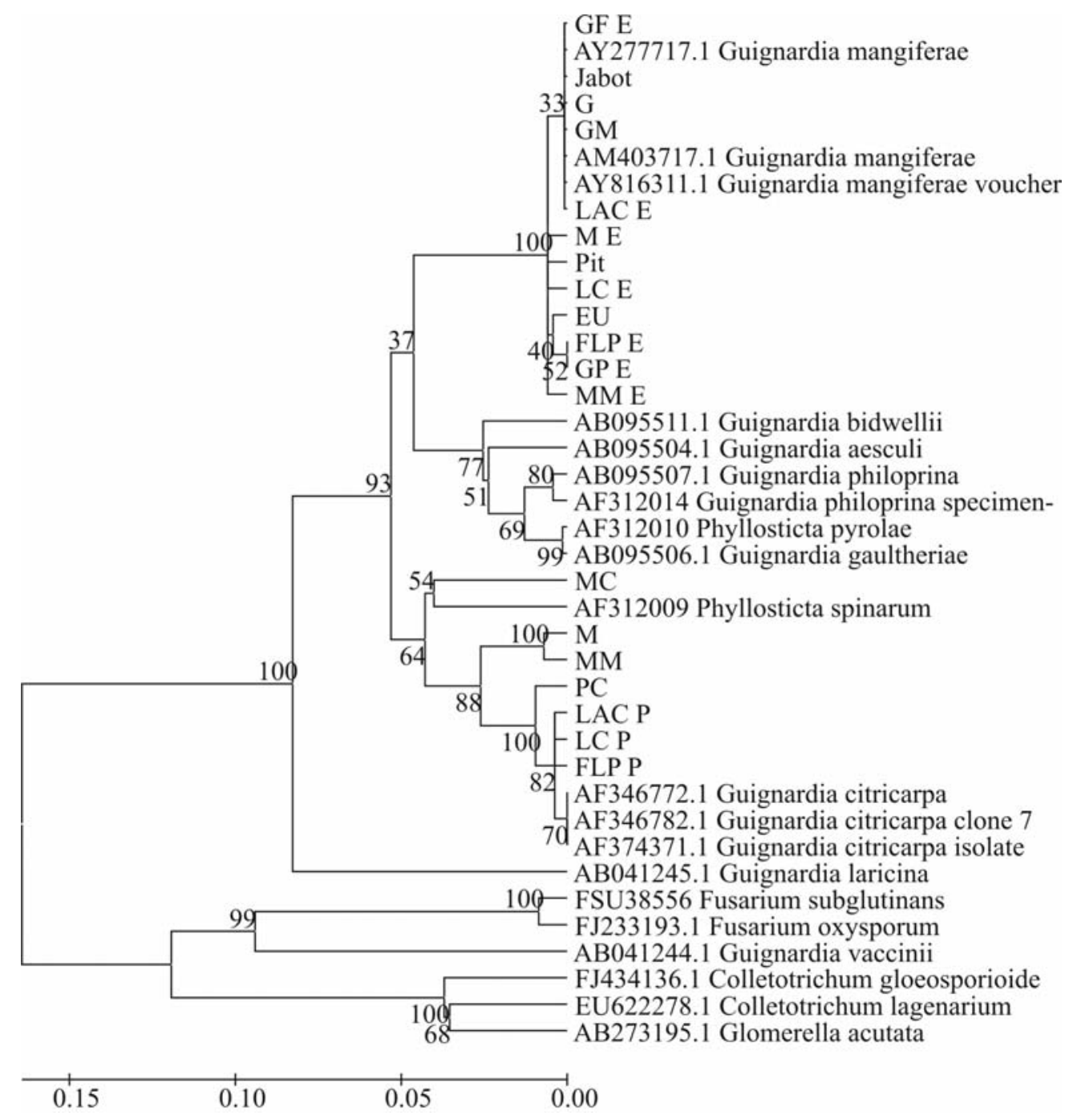

FIGURA 11- Dendrograma obtido através de sequências consenso das regiões ITS1-5,8S-ITS2 de cada um dos grupos de isolados formados em cada hospedeiro. Verifica-se que os isolados agruparamse de acordo com sua similaridade em relação às sequências-padrão obtidas em banco de dados.

\section{CONCLUSÕES}

1-Fungos da espécie G. citricarpa foram encontrados unicamente em citros.

2-Fungos da espécie G. mangiferae foram encontrados em diferentes hospedeiros.

3-Fungos causadores de podridão em frutos de goiabeira foram identificados como G. mangiferae de acordo com a análise das regiões ITS1-5,8S-ITS2.

4-Plantas de mangueira são hospedeiras de duas formas de Guignardia ainda não identificadas em nível de espécie, além de G. mangiferae.

5-Plantas de pitangueira e jabuticabeira são hospedeiras de G. mangiferae.

\section{AGRADECIMENTOS}

Agradecemos a FAPESP (Fundo de Amparo à Pesquisa do Estado de São Paulo) pelo financiamento deste trabalho através dos projetos 04/10560-4 (Pós-Doutoramento do primeiro autor), 06/51941-6 (Iniciação Científica) e 01/10993-0 (Projeto Temático), bem como ao CNPq e CAPES pela concessão de bolsas de Iniciação Científica, Doutorado e Produtividade em Pesquisa. 
ANEXO 1- Relação dos isolados utilizados neste trabalho com os respectivos números de acesso no GenBank.

\begin{tabular}{|c|c|c|c|c|}
\hline Isolado // ID GenBank & Isolado // ID GenBank & Isolado // ID GenBank & Isolado // ID GenBank & Isolado // ID GenBank \\
\hline G-10 // FJ769581 & GP1_1// FJ769619 & LAC_8 // FJ769657 & LC-25 // FJ769695 & MM-15 // FJ769733 \\
\hline G-11 // FJ769582 & GP1_2 // FJ769620 & LAC_9 // FJ769658 & LC-26 // FJ769696 & MM-16 // FJ769734 \\
\hline G-12 // FJ769583 & GP1_3 // FJ769621 & PC-10 // FJ769659 & LC-27 // FJ769697 & MM-17 // FJ769735 \\
\hline G-13 // FJ769584 & EU-1 // FJ769622 & PC-11 // FJ769660 & LC-29 // FJ769698 & MM-19 // FJ769736 \\
\hline G-14 // FJ769585 & EU-2 // FJ769623 & PC-12 // FJ769661 & LC-2 // FJ769699 & MM-1 // FJ769737 \\
\hline G-15 // FJ769586 & EU-3 // FJ769624 & PC-13 // FJ769662 & LC-31 // FJ769700 & MM-20 // FJ769738 \\
\hline G-16 // FJ769587 & EU-4 // FJ769625 & PC-14 // FJ769663 & LC-3 // FJ769701 & MM-21 // FJ769739 \\
\hline G-17 // FJ769588 & EU-5 // FJ769626 & PC-15 // FJ769664 & LC-4 // FJ769702 & MM-22 // FJ769740 \\
\hline G-18 // FJ769589 & EU-6 // FJ769627 & PC-16 // FJ769665 & LC-7 // FJ769703 & MM-23 // FJ769741 \\
\hline G-19// FJ769590 & EU-7 // FJ769628 & PC-17 // FJ769666 & LC-8 // FJ769704 & MM-2 // FJ769742 \\
\hline G-1 // FJ769591 & EU-8 // FJ769629 & PC-18 // FJ769667 & LC-9 // FJ769705 & MM-3 // FJ769743 \\
\hline G-20 // FJ769592 & EU-9 // FJ769630 & PC-19 // FJ769668 & LC-14 // FJ769706 & MM-4 // FJ769744 \\
\hline G-21 // FJ769593 & EU-10 // FJ769631 & PC-1 // FJ769669 & LC-19 // FJ769707 & MM-5 // FJ769745 \\
\hline G-22 // FJ769594 & EU-11 // FJ769632 & PC-20 // FJ769670 & M-10 // FJ769708 & MM-6 // FJ769746 \\
\hline G-23 // FJ769595 & EU-12 // FJ769633 & PC-21 // FJ769671 & M-11 // FJ769709 & MM-7 // FJ769747 \\
\hline G-24 // FJ769596 & FLP-15 // FJ769634 & PC-24 // FJ769672 & M-13 // FJ769710 & MM-8 // FJ769748 \\
\hline G-26 // FJ769597 & FLP-25 // FJ769635 & PC-26 // FJ769673 & M-14 // FJ769711 & MM-9 // FJ769749 \\
\hline G-2 // FJ769598 & FLP-4 // FJ769636 & PC-27 // FJ769674 & M-15 // FJ769712 & Pit1 // FJ769750 \\
\hline G-3 // FJ769599 & FLP-6 // FJ769637 & PC-2 // FJ769675 & M-1 // FJ769713 & Pit3 // FJ769751 \\
\hline G-4 // FJ769600 & FLP-12 // FJ769638 & PC-3 // FJ769676 & M-2 // FJ769714 & Pit4 // FJ769752 \\
\hline G-5 // FJ769601 & FLP-14 // FJ769639 & PC-6 // FJ769677 & M-3 // FJ769715 & Pit6 // FJ769753 \\
\hline G-6 // FJ769602 & FLP-16 // FJ769640 & PC-9 // FJ769678 & M-4 // FJ769716 & Pit7 // FJ769754 \\
\hline G-7 // FJ769603 & FLP-17 // FJ769641 & PC-4 // FJ769679 & M-5 // FJ769717 & Pit8 // FJ769755 \\
\hline G-8 // FJ769604 & FLP-19 // FJ769642 & PC-5 // FJ769680 & M-6 // FJ769718 & Pit9 // FJ769756 \\
\hline G-9 // FJ769605 & FLP-21 // FJ769643 & PC-22 // FJ769681 & M-7 // FJ769719 & Pit10 // FJ769757 \\
\hline GM-10 // FJ769606 & FLP-23 // FJ769644 & PC-7 // FJ769682 & M-8 // FJ769720 & Pit11 // FJ769758 \\
\hline GM-1 // FJ769607 & Jabot1 // FJ769645 & LC-10 // FJ769683 & M-9 // FJ769721 & Pit12 // FJ769759 \\
\hline GM-2 // FJ769608 & Jabot2 // FJ769646 & LC-11 // FJ769684 & MC-1 // FJ769722 & Pit13 // FJ769760 \\
\hline GM-3 // FJ769609 & Jabot3 // FJ769647 & LC-12 // FJ769685 & MC-2 // FJ769723 & Pit14 // FJ769761 \\
\hline GM-4 // FJ769610 & Jabot5 // FJ769648 & LC-13 // FJ769686 & MC-3 // FJ769724 & Pit15 // FJ769762 \\
\hline GM-5 // FJ769611 & Jabot6 // FJ769649 & LC-15 //FJ769687 & MC-4 // FJ769725 & Pit16 // FJ769763 \\
\hline GM-6 // FJ769612 & LAC_1 // FJ769650 & LC-16 // FJ769688 & MC-6 // FJ769726 & Pit18 // FJ769764 \\
\hline GM-7 // FJ769613 & LAC_2 // FJ769651 & LC-17 // FJ769689 & MC-7 // FJ769727 & Pit19 // FJ769765 \\
\hline GM-8 // FJ769614 & LAC_3 // FJ769652 & LC-18 // FJ769690 & MM-10 // FJ769728 & Pit20 // FJ769766 \\
\hline GM-9 // FJ769615 & LAC_4 // FJ769653 & LC-1 // FJ769691 & MM-11 // FJ769729 & Pit21 // FJ769767 \\
\hline GF-1 // FJ769616 & LAC_5 // FJ769654 & LC-20 // FJ769692 & MM-12 // FJ769730 & Pit22 // FJ769768 \\
\hline GF-2 // FJ769617 & LAC_6 // FJ769655 & LC-22 // FJ769693 & MM-13 // FJ769731 & Pit23 // FJ769769 \\
\hline GF-3 // FJ769618 & LAC_7 // FJ769656 & LC-23 // FJ769694 & MM-14 // FJ769732 & Pit24 // FJ769770 \\
\hline
\end{tabular}




\section{REFERÊNCIAS}

ALTSCHUL, S. F.; MADDEN, T. L.; SCHAFFER, A. A.; ZHANG, J.; ZHANG, Z.; MILLER, W.; LIPMAN, D. J. Gapped BLAST and PSI-BLAST: a new generation of protein database search programs. Nucleic Acids Research, Oxford, v. 25, p. 3389-3402, 1997.

BAAYEN, R. P.; BONANTS, P. J. M.; VERKLEY, G.; CARROLL, G. C.; VAN DERAA, H.A.; DE WEERDT, M.; VAN BROUWERSHAVEN, I. R.; SCHUTTE, G. C.; MACCHERONI, W. JR.; GLIENKE DE BLANCO, C.; AZEVEDO, J. L. Nonpathogenic isolates of the citrus black spot fungus, Guignardia citricarpa, identified as a cosmopolitan endophyte of woody plants, G. mangiferae (Phyllosticta capitalensis). Phytopathology, St. Paul, v. 92, p. 464-477, 2002.

BACIARELLEI-FALINI, L.; RUBINI, A.; RICCIONI, C.; PAOLOCCI, F. Morphological and molecular analysis of ectomycorrhizal diversity in a man-made T. melanosporum plantation: description of a novel truffle-like morphotypes. Mycorrhiza, Heidelberg, v. 16, p. 474-484, 2006

BALDASSARI, R. B.; WICKERT, E.; GOES, A. Pathogenicity, colony morphology and diversity of isolates of Guignardia citricarpa and G. mangiferae isolated from Citrus spp. European Journal of Plant Pathology, Netherlands, v. 120, p. 103-110, 2008.

BRIDGE, P. D.; SPOONER, B. M.; ROBERTS, P. J. The impact of molecular data in fungal systematic. Advances in Botanical Research, Birmingham, v. 42, p. 33-67, 2005.

CROUWS, P. W. The impact of molecular phylogenetics on the taxonomy and diagnostics of fungi. EPPO Bulletin, Germany, v. 35, p. 47-51, 2005.

CROUWS, P. W.; GAMS, W.; STALPERS, J. A.; ROBERT, V.; STEGEHUIS, G. Mycobank: na online initiative to launch mycology into the 21st century. Studies in Mycology, Netherlands, v.50, p.19-22, 2004.

DRESLER-NURMI, A.; KAIJALAINEM, S.; LINDSTROM, K.; HATAKKA, A. Grouping of lignin degrading corticiod fungi based on RFLP analysis od 18S rDNA and ITS regions. Mycological Research, Cambridge, v. 103, p. 990-996, 1999.
GARGAS, A.; DEPRIEST, P. T. 1996. A nomenclature for fungus PCR primers with examples from introncontaining Ssu rDNA. Mycologia, Stanford, v. 88, p. 45-748, 1996.

GORDON, D.; ABAJIAN, C.; GREEN, P. Consed: a graphical tool for sequence finishing. Genome Research, Stanford, v. 8, p. 195-202, 1998.

KIMURA, M. A simple method for estimating evolutionary rates of base substitutions through comparative studies of nucleotide sequences. Journal of Molecular Evolution, New York, v.16, p. 111-120, 1980.

KOGEL, K. H.;FRANKEN, P.;HÜCKELHOVEN,R. Endophyte or parasite - what decides? Current Opinion in Plant Biology, Berlim, v.9, p. 358-363, 2006.

KUMAR, S.; TAMURA, K.; NEI, M. MEGA3: Integrated software for Molecular Evolutionary Genetics Analysis and sequence alignment. Briefings in Bioinformatics, Oxford, v. 5, p. 150163, 2004.

KURAMAE-IZIOKA, E. E. A rapid, easy and high yield protocol for total genomic DNA isolation of Colletotrichum gloesporioides and Fusarium oxysporum. Revista Unimar, Marília, v.19, p. 683689, 1997.

MCMILLAN Jr.; R. T. Guignardia citricarpa a cause of black spot on mango foliage in Florida. Journal of Phytopathology, Berlim, v. 117, p. 260-264, 1986.

NEI, M.; KUMAR, S. Molecular evolution and phylogenetics. Oxford: Oxford University Press, 2000.333 p.

NEI, M. Genetic distance between populations. American Naturalist, Chicago, v. 106, p. 283- 292, 1972.

OKANE, I.; LUMYONG, S.; NAKAGIRI, A.; ITO, T. Extensive host range of an endophytic fungus Guignardia endophyllicola (anamorph: Phyllosticta capitalensis). Mycoscience, Japan, v. 44, p. 353-363, 2003.

OKANE, I.; NAKAGIRI, A.; ITO, T.Identity of Guignardia sp. inhabiting ericaceous plants. Canadian Journal of Botany, Ontario, v. 79, p. 101109, 2001. 
RISTAINO, J.B.; MADRITCH, M.; TROUT, C. L.; PARRA, G. PCR amplification of ribosomal DNA for species identification in genus Phytophtora. Applied and Environmental Microbiology, Yale, v. 63, p. 948954, 1998.

ROBBERTSE, B.; REEVES, J. B.; SCHOCH, C. L.; SPATAFORA, J. W. A phylogenomic analysis of the Ascomycota. Fungal Genetics and Biology, New York, v. 43, n.10, p. 715-725, 2006.

RODRIGUES, K. F.; SIEBER, T. N.; GRÜNIG, C.; HOLDENRIDER, O. Characterization of Guignardia mangiferae isolated from tropical plants based in morphology, ISSR-PCR amplifications and ITS1-5.8SITS2 sequences. Mycological Research, Cambridge, v. 108, p. 45-52, 2004.

SAITOU, N.; NEI, M. The neighbor-joining metod: a new method for constructing phylogenetic trees. Molecular Biology and Evolution, Oxford, v. 4, p. 406-425, 1987.
SCHULTZ, B.; BOYLE, C. The endophytic continuum. Mycological Research, Londres, v. 109, n. 6, p. 661-686, 2005.

SUTTON, B.C.; WATERSTON, J.M. Guignardia citricarpa. Kew: Commonwealth Mycological Institute, 1985. (Descriptions of Pathogenic fungi and bacteria, 85)

TOZELLO, L. J.; RIBEIRO, W. R. C. Tratamento póscolheita de goiaba (Psidium guajava L.) contra podridão de Guignardia psidii. Revista Brasileira de Fruticultura, Jaboticabal, v. 20, n. 2, p. 229-234, 1998.

WHITE, T. J.; BRUNS, T.; LEE, S.; TAYLOR, J. W. Amplification and direct sequencing of fungal ribosomal RNA genes for phylogenetics. In: PCR Protocols: A guide to methods and applications. San Diego: Academic Press, 1990. p. 315-322.

XU, J. Fundamentals of Fungal Molecular Population Genetic Analysis. Current Issues in Molecular Biology, Norwish, v. 8, p. 75-90, 2006. 